\title{
Science that matters
}

\section{Climate change research can influence policy decisions, but needs to stretch its boundaries.}

The production of policy-relevant research has become a central mandate in the climate change scientific domain, as highlighted by the sheer number of published articles on policy issues.

Climate scientists understand that they play a critical role in informing the policy decision-making process. Many of them work remarkably hard to produce more robust greenhouse gas emissions estimations in relation to climate change targets. The hope, at present, is to illuminate governments gathering together at several upcoming international United Nations meetings, starting this September in New York, to initiate the process that will lead to a new global climate change agreement at the end of next year in Paris.

But scientists do more than just that. They also investigate what mitigation options those estimations entail, including solutions to deliver negative emissions (see Commentary by Fuss et al. on page 850 of this issue). They even discuss how countries could effectively and fairly share the carbon emissions mitigation burden to avoid dangerous climate change, as highlighted in a Perspective by Raupach et al. on page 873. Supposedly all this work, represented at its highest synthesis by the Intergovernmental Panel on Climate Change reports, feeds policy discussions and therefore is policy-relevant. Yet, global climate change policy is not delivering solutions in line with scientific knowledge. We all know this, and scientists now more than ever agree that it's the case. One would expect that, as a result, some changes in both scientific and policy practices would have already begun. Indeed, awareness about the need for change in the science-policy domain is gradually emerging within the broad climate change community, but the way forward remains blurry.

Social scientists are concerned about the nature of the gap between science and policy. Many think that without revisiting the lens through which natural scientists look at policy on one side, and the way negotiators frame policy goals on the other, the gap will remain. In a Commentary on page 853 , David Victor lucidly underlines how most of the policy-relevant climate science practice develops around the idealistic view that governments "separate the decisions about how much warming is tolerable from the choices about who pays for policy action". He goes on to suggest that somehow even diplomats contribute to the same vision by setting "abstract global goals". This would explain at least in part why the science-policy gap remains. What's next? There are many calls for the proper integration of the social sciences into the climate change research agenda as a crucial step to fill the gap, and to reframe the policy-relevant research questions. However, making this happen hinges on a number of challenging steps, including broadening the notion of scientific relevance and excellence beyond conventional criteria and revisiting our understanding of the societal importance of science. Such a process cannot be accomplished by scientists alone, no matter what research field they belong to. Research funders, scientific outlets, governments and ultimately the public all have a role to play.

Published online: 21 September 2014

\section{What's your story?}

\section{An understanding of the personal frameworks we use to absorb and contextualize climate change information might help us to have more fruitful exchanges about climate policy.}

The author Terry Pratchett famously suggested that the species name for humans, Homo sapiens ('wise man'), is quite wrong, with "wisdom being one of our least evident features". Rather he suggested that we should be named "Pan narrans, the storytelling chimpanzee”. Certainly we tell ourselves stories to make sense of the world around us and these narratives form the context in which we interpret events as they unfold. Climate change is - perhaps because of its cross-cutting nature - particularly open to being interpreted within a multitude of different overarching narratives, or frames. Consequently, many disagreements about facts and figures seem to be, at bottom, due to disagreements about the fundamental story into which these details fit, rather than facets of the details themselves. These issues of framing are well known to psychologists and sociologists, among others, having already been applied to climate change and communication in particular (for example, M. C. Nisbet Environ. Sci. Policy Sust. Dev. 51, 12-23; 2009). Indeed, framing is becoming something of a buzz word in climate change circles. Nevertheless, the frequency with which climate change discussions are confounded by (often unstated) assumptions related to different personal, political or intellectual framings of the issues suggests that there remains great scope for these ideas to be spread and implemented to facilitate a clearer more nuanced dialogue between the various actors involved in climate change. Part of this will no doubt involve scholarly work to develop and apply these concepts. However, there also seems to be significant scope for individuals to investigate their own stories and those of their friends and colleagues as a way to help contextualize and explain their work and highlight their own ethical and political values. Like it or not, these values influence our personal framings and consequently the way that we all make sense of the facts and figures at our disposal. This effect seems particularly important when information is used not just to investigate the various aspects of the 'climate change problem' but also to inform or advocate policy solutions, which necessarily involve aspirational goals.

The stories we construct to contextualize climate change and formulate policy responses are not only important for their role in shaping our goals and objectives, but also have the capacity to inspire or demotivate. The next year promises to be an important time for progress on climate change, sustainable development and poverty alleviation. In this context, it seems important to develop stories that recognize the scale of these challenges and acknowledge the limited progress to date, but at the same time continue to inspire individuals to strive for progress. 